\title{
Monitoring of Dopamine Metabolism by In Vivo Voltammetry and High Performance Liquid Chromatography in L-DOPA-Treated Rats
}

\author{
Shigeo AOKI, Kohki INUKAI, Miyuki SAKURAI, Noriaki KOSHIKAWA* \\ and Masafumi KOBAYASHI \\ Department of Pharmacology. Nihon University School of Dentistry. \\ 1-8-13. Kanda-Surugadai, Chiyoda-ku, Tokyo 101, Japan
}

Accepted November 8, 1986

\begin{abstract}
Following L-DOPA administration. DA metabolites were measured by both in vivo voltammetry and HPLC-ECD. In vivo, the amplitudes of the catechol oxidation currents in both the striatum and frontal cortex increased and reached a plateau from $60 \mathrm{~min}$ to 240 min after L-DOPA treatment. L-DOPA. DA. DOPAC and HVA levels measured by HPLC-ECD after L-DOPA treatment were increased in both regions, and the occurrence of the peak of each compound was dependent on its order in the metabolic pathway, i.e., $15 \mathrm{~min}$ for DA. $45 \mathrm{~min}$ for DOPAC and 60-180 min for HVA. However, NE remained unchanged. No indication of a rapid DA increase was apparent in the catechol oxidation current at 15 min; and thus, DA is unlikely to be a main contributor to the catechol oxidation current in the brain of rats treated with L-DOPA.
\end{abstract}

In vivo application of differential pulse voltammetry in the brain of unanaesthetized freely moving rats has recently been developed (1-3); and with this method, it is possible to monitor changes in brain catechols and indoles $(1,3)$. One limitation of the technique is the composite nature of the voltammetric signal, which complicates interpretation of the data. Pharmacological investigations suggest that the catechol oxidation current measured in vivo is attributable to extracellular 3.4-dihydroxyphenylacetic acid (DOPAC) (4,5). However, when brain dopamine (DA) concentrations are increased after $\mathrm{L}$-dihydroxyphenylalanine (L-DOPA) injection, it is suspected that the DA synthesized from L-DOPA may contribute to the catechol oxidation peak. To test this hypothesis, L-DOPA was administered and the concentrations of L-DOPA, DA, norepinephrine (NE), DOPAC and homovanillic acid (HVA) in the striatum and cortex were measured by high-performance liquid chromatography connected to electro-

\footnotetext{
* To whom correspondence should be addressed.
}

chemical detection (HPLC-ECD) at the time points used for the in vivo voltammetry.

A similar experiment has been done by Hefti and Melamed (6). However, the electrodes (carbon paste) employed in their study could not exclude the interference by ascorbic acid or other oxidizable compounds not related to catechols. The technique we employed in the present study was based on Ikeda's report (3): this enables the separation of catechols from ascorbic acid or other oxidizable compounds. Such a technique seems to be more suitable for measuring catechol oxidation current.

Carbon fiber working electrodes (type WM-100, Shionogi Co., Ltd., Osaka), pretreated with a triangular pulse $(\mathrm{O}-2 \mathrm{~V}, 2.5$ pulses/sec for $30 \mathrm{sec}$ ) in $2 \mathrm{mM} \mathrm{H}_{2} \mathrm{SO}_{4}$ (3). were implanted into the striatum (ant, 8.2; vert, 0; lat, 3.0) and the frontal cortex (ant, 8.2; vert, 2.5; lat, 3.0) of male Wistar rats $(200-250 \mathrm{~g})$ under sodium pentobarbitone (50 $\mathrm{mg} / \mathrm{kg}$ ) anaesthesia, according to the atlas of König and Klippel (7). Reference (Ag$\mathrm{AgCl})$ and auxiliary $(\mathrm{Ag})$ electrodes were placed on the surface of the cortex, and all 
the electrodes were fixed to the skull using dental cement. The animals were allowed to recover for 2 days before use. Voltammetric measurements were made (DPV-5, Tokaiirika) with the following parameter settings based on Ikeda's report (3): potential sweep: $-200 \mathrm{mV}$ to $+500 \mathrm{mV}$. pulse amplitude: 50 $\mathrm{mV}$, scan rate: $25 \mathrm{mV} / \mathrm{sec}$, pulse duration: $50 \mathrm{msec}$, sampling period: $20 \mathrm{msec}$, and a pulse frequency of 10 pulses $/ \mathrm{sec}$. To reduce interference by ascorbate, an oxidation potential (+50 mV) was applied to the working electrode for $3 \mathrm{~min}$ just before measurements were made. At the end of each experiment, electric lesions were made by passing a current $(10 \mu \mathrm{A}, 20 \mathrm{sec})$ through the working electrode and the location of the electrode tip was verified histologically.

Rats were sacrificed by microwave irradiation at $1.5 \mathrm{~kW}$ for $1.3 \mathrm{sec}$ (NJE 2601 . New Japan Radio Co., Ltd.) at various times after L-DOPA (200 mg/ $\mathrm{kg}$, i.p.) injection. The brains were removed, and tissue samples from the striatum and frontal cortex were dissected from two $600 \mu \mathrm{m}$ thick brain slices according to the atlas of König and Klippel (7).

L-DOPA and its metabolites were determined by HPLC-ECD. For the L-DOPA, DA and NE assays, each tissue was sonicated in a solution containing $25 \mu \mathrm{l}$ of $0.4 \mathrm{~N}$ perchloric acid, $40 \mu$ of $0.1 \mathrm{M}$ Tris- $\mathrm{HCl}$ buffer $(\mathrm{pH} 8.5)$ and $10 \mu \mathrm{l}$ of $0.1 \mathrm{M}$ EDTA-2Na after addition of $50 \mathrm{ng}$ 3,4-dihydroxybenzylamine dissolved in $10 \mu \mathrm{l} 0.1 \mathrm{~N}$ perchloric acid as an internal standard. After $10 / 1$ was taken for protein assay. $50 \mu \mathrm{l}$ of chloroform was added to the homogenates according to the method of Kaneno et al. (8). The $\mathrm{pH}$ of the supernatant was adjusted to $8.0-8.5$ by the addition of $0.25 \mathrm{~N} \mathrm{NaOH}$, and then $5 \mathrm{mg}$ of activated alumina were added and the mixture was shaken for $15 \mathrm{~min}$. After the aqueous phase was discarded, the alumina were washed 3 times with 500 kl of doubledistilled water. Following addition of $40 \mu \mathrm{l}$ of $0.1 \mathrm{~N} \mathrm{HCl}$ to the alumina, the supernatant was applied to an HPLC column (Nucleosil 7C18). The mobile phase was $0.05 \mathrm{M}$ phosphate buffer ( $\mathrm{pH} 3.1$, containing $10 \%$ methanol. $0.5 \mathrm{mM}$ heptanesulfonic acid and $2 \mu \mathrm{M}$ EDTA-2Na). The detector potential was set at $+0.7 \mathrm{~V}$ versus an $\mathrm{Ag} / \mathrm{AgCl}$ reference electrode, and the flow-rate was $0.8 \mathrm{ml} / \mathrm{min}$.

For DOPAC and HVA assays, each tissue was sonicated in $100 \mu$ of $0.1 \mathrm{~N}$ perchloric acid after addition of $20 \mathrm{ng}$ 3,4-dihydroxyphenylpropionic acid in $10 / \mu$ of perchloric acid as an internal standard. After $10 \mu \mathrm{l}$ was taken for the protein assay. $50 \mu$ of chloroform was added to the homogenates, and the mixture was vortexed and centrifuged at $6500 \times \mathrm{g}$ for $15 \mathrm{~min}$. The supernatant was applied to the HPLC column (Nucleosil 7C18). The mobile phase was $0.05 \mathrm{M}$ phosphate buffer ( $\mathrm{pH}$ 4.8, containing $20 \%$ methanol and 2 " $\mathrm{M}$ EDTA-2Na). The detector potential was set at $+0.8 \mathrm{~V}$ versus an $\mathrm{Ag} /$ $\mathrm{AgCl}$ reference electrode, and the flow-rate was $0.8 \mathrm{ml} / \mathrm{min}$.

Protein was assayed according to the method of Lowry et al. (9).

In a study using various solutions, LDOPA, DA. NE and DOPAC (dissolved in phosphate-buffered saline, $\mathrm{pH}$ 7.4) were detected at the catechol oxidation potential (approximately $+100 \mathrm{mV}$ ). The highest detection sensitivity was found with DA: and the sensitivities of NE, L-DOPA and DOPAC were $84 \%, 8 \%$ and $2 \%$ of that of DA, respectively. 3-Methoxytyramine (3-MT) and HVA were detected at the indole oxidation potential (approximately $+300 \mathrm{mV}$ ), and the sensitivities of 3 -MT and HVA were $22 \%$ and $1 \%$ of 5 -hydroxytryptamine, respectively

In vivo, the amplitudes of the catechol oxidation current after L-DOPA treatment in both the striatum and the frontal cortex were rapidly increased and reached a plateau from $60 \mathrm{~min}$ to $240 \mathrm{~min}$ (Fig. 1).

L-DOPA, DA, DOPAC and HVA levels measured by HPLC-ECD after L-DOPA treatment were increased in both the striatum and frontal cortex; and the occurrence of the peak of each compound was dependent on its order in the metabolic pathway, i.e., $15 \mathrm{~min}$ for DA, $45 \mathrm{~min}$ for DOPAC and 60-180 min for HVA (Fig. 2). However, NE remained unchanged (Fig. 2).

Following L-DOPA injection, maximum increases in DA concentrations in both the striatum and frontal cortex were found after $15 \mathrm{~min}$ : they returned to the pre-injection 


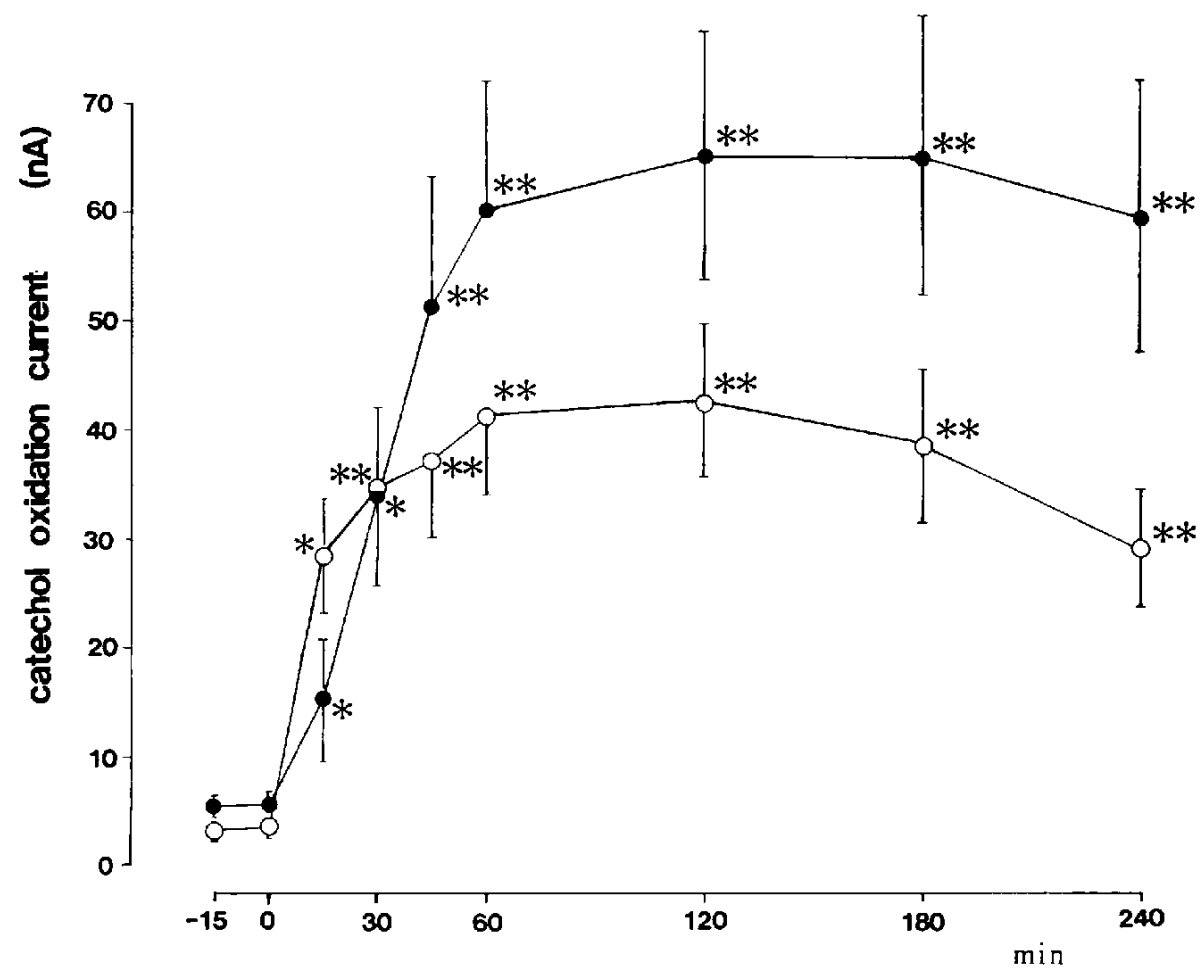

Fig. 1. Catechol oxidation currents in both the striatum ( - - ) and frontal cortex ( $-O-)$ of rats treated with L-DOPA $(200 \mathrm{mg} / \mathrm{kg}$, i.p.). Each value is the mean of 7 rats, the bars indicating S.E.M. ${ }^{*} P<0.05,{ }^{* *} P<0.01$, difference from the zero point (paired $t$-test)

levels by $120 \mathrm{~min}$. However, at $15 \mathrm{~min}$, no sign of a rapid DA increase was reflected in the catechol oxidation current even though the sensitivity of the electrode for DA is 50-fold higher than that for DOPAC: thus, after L-DOPA treatment, the amplitudes of the catechol oxidation currents at both sites increased smoothly until $60 \mathrm{~min}$ and plateaued thereafter. Our data supports the belief that L-DOPA is intracellularly decarboxylated to DA after it is taken up not only by dopaminergic neurones but also by glial cells (10): this results in increased intracellular DA being available for release from neurones but not in an increase in extracellular DA concentrations. In contrast to our results, Hefti and Melamed (6) reported an increase of released extracellular DA measured by in vivo voltammetry after $(15-90 \mathrm{~min})$ L-DOPA administration. This discrepancy seems to be mainly due to the difference in technique employed, since the electrodes used by Hefti and Melamed (6) are thought to detect not only catechols but also other oxidizable compounds (e.g., ascorbic acid). Other authors (11) have reported that administration of L-DOPA doubled the observed concentration of DA released by electrical stimulation, but that the released DA was immediately reuptaken (rate of DA uptake was unchanged).

The high catechol oxidation current observed from $60 \mathrm{~min}$ to $240 \mathrm{~min}$ after LDOPA injection was not directly reflected by cerebral DOPAC concentrations. The maximum DOPAC levels in both the striatum and frontal cortex were found at $45 \mathrm{~min}$ and gradually decreased thereafter. Therefore, part of the DOPAC which may have diffused into the extracellular space is the possible main contributor to the catechol oxidation current. It can be assumed that this extracellular DOPAC was detected by in vivo voltammetry just before it was converted to 

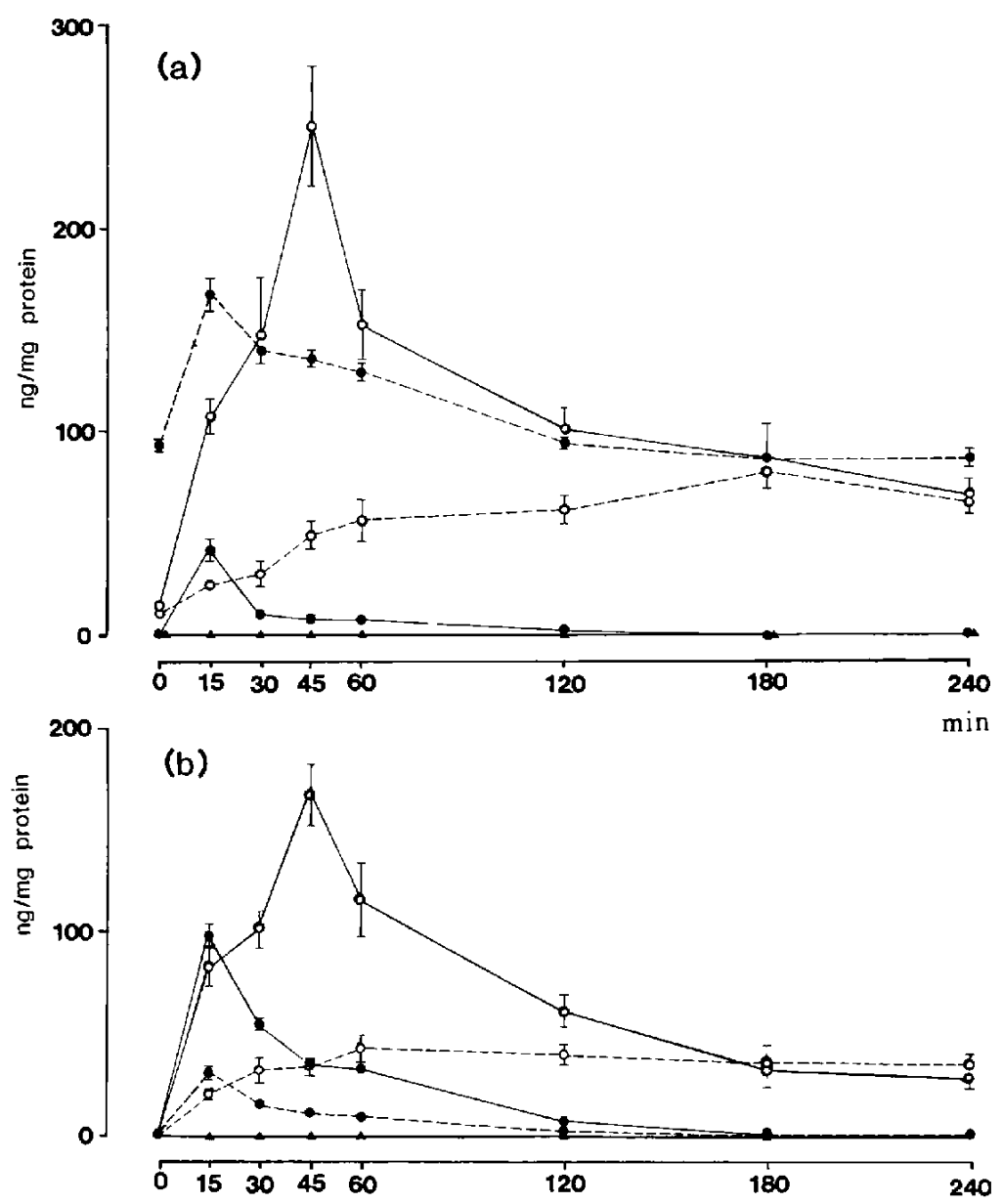

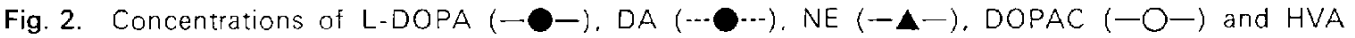
$\left(--O^{-\cdots}\right)$ after L-DOPA (200 mg/kg, i.p.) injection in both the striatum (a) and frontal cortex (b). Each value is the mean of 8 rats, the bars indicating S.E.M.

HVA since the pattern of the catechol oxidation current after L-DOPA treatment is between those of DOPAC and HVA.

Acknowledgements: This work was supported by the Satoh Foundation. We are grateful to Dr. I.C. Campbell for his valuable comments.

\section{References}

1 Crespi, F., Paret, J., Keane, P.E. and Morre, M.: An improved differential pulse voltammetry technique allows the simultaneous analysis of dopaminergic and serotonergic activities in vivo with a single carbon-fibre electrode. Neurosci. Lett. 52, 159-164 (1984)

2 Gonon, F., Buda, M., Cespuglio, R., Jouvet, $M$. and Pujol, J.F.: Voltammetry in the striatum of chronic freely moving rats: Detection of catechols and ascorbic acid. Brain Res. 223, 69-80 (1981)

3 Ikeda, M., Miyazaki, H., Mugitani, N. and Matsushita, A.: Simultaneous monitoring of 3,4dihydroxyphenylacetic acid (DOPAC) and 5hydroxyindoleacetic acid (5-HIAA) levels in the brains of freely moving rats by differential pulse voltammetry technique. Neurosci. Res. 1, 171184 (1984)

4 Gonon, F., Buda, M., Cespuglio, R., Jouvet, M. and Pujol, J.F.: In vivo electrochemical detection of catechols in the neostriatum of anaesthetized rats: Dopamine or DOPAC? Nature 286, 902-904 (1980)

5 Sharp, T., Maidment, N.T., Brazell, M.P., Zetterstrom, T., Ungerstedt, U., Benmett, G.W. and Marsden, C.A.: Changes in monoamine 
metabolites measured by simultaneous in vivo differential pulse voltammetry and intracerebral dialysis. Neuroscience 12, 1213-1221 (1984)

6 Hefti, F. and Melamed, E.: Dopamine release in rat striatum after administration of L-DOPA as studied with in vivo electrochemistry. Brain Res. 225, 333-346 (1981)

7 König, J.F.R. and Klippel, R.A.: The Rat Brain, A Stereotaxic Atlas of the Forebrain and Lower Part of the Brain Stem. Williams and Wilkins. Baitimore (1963)

8 Kaneno, S., Watanabe, A. and Takahashi, R.: Alteration of striatal dopaminergic function implicated in methamphetamine-induced reverse tolerance in rats. Eur. J. Pharmacol. 123, 287-
$294(1986)$

9 Lowry, O.H., Rosebrough, N.J., Farr, A.L. and Randall, R.J.: Protein measurement with the Folin phenol reagent. J. Biol. Chem. 193, 254275 (1951)

10 Kruk, Z.L. and Pycock, C.J.: Therapeutic applications and consequences of drugs acting at doparninergic synapses. In Neurotransmitters and Drugs, p. 81-93, Croom Helm Ltd., London (1979)

11 Stamford, J.A., Kruk, Z.L., Millar, J. and Wightman, R.M.: Striatal dopamine uptake in the rat: In vivo analysis by fast cyclic voltammetry. Neurosci. Lett. 51, 133-138 (1984) 